universalismo como del nacionalismo. En un caso, por su tendencia a suprimir las diferencias imponiendo normas unitarias, y en otro, por sus tendencias a homogenizar de fuera hacia dentro para diferenciarse como una unidad homogénea de dentro hacia fuera. Frente a ambos modelos, el cosmopolitismo que define a Europa se rige por el esquema «no sólo sino también» y plantea «percibir a los otros como diferentes $y$ como iguales». Todo ello en el bien entendido que lo ajeno no sólo constituye un valor en sí, además supone una oportunidad para un mejor autoconocimiento y para experimentar con los propios límites.

Por otra parte, los autores hablan de imperio para definir los contornos políticos y jurídicos que sobre la marcha va adquiriendo el proceso europeo. A pesar de las reticencias que el concepto despierta por evocar experiencias históricas de hegemonía y dominación, el imperio europeo se caracteriza por la flexibilidad de sus fronteras, por la constante renegociación de las mismas y por su apertura discursiva hacia el exterior y hacia los otros. Frente a otros modelos de imperio, como el del Estado moderno, su fuerza no es la edificación de límites excluyentes, sino la de la expansión integradora de nuevos socios con los que compartir experiencias y destino. Se trata de un imperio sin imperator, cuyos rasgos más marcados son, por un lado, una forma no jerárquica de toma de decisiones y de participación de los actores estatales en el proceso de decisión europeo y, por otro, la participación de un gran número de actores sociales (grupos de interés, empresas, actores de la sociedad civil) en las decisiones políticas. Al mismo tiempo, se dispone sobre una estructura reticular en la que el poder no puede concentrarse en la cúspide, sino que se sitúa en los puntos de encuentro e intersección entre las distintas instituciones y niveles del sistema. El poder abandona el centro y se sitúa en los márgenes.

En definitiva, Europa parece encontrarse en un momento de tránsito que obliga a la opinión pública y a la ciencia social a debatir acerca de sus procesos políticos y sociales en curso. En buena medida, estas reflexiones pretenden contribuir a clarificar su momento actual y a derribar imágenes gastadas que impiden ver lo que define su verdadera entraña: el desafío, el experimento, la transgresión; en definitiva, un ejercicio de autorreflexividad permanente.

Celso SÁNCHEZ CAPDEQUÍ

\section{Mauro F. Guillén \\ The Taylorized Beauty of the Mechanical. Scientific Management and the Rise of Modernist Architecture}

(Princeton University Press, 2006)

Uno se puede preguntar qué hace un catedrático de Sociología, experto en globalización y teorías de la organización, escribiendo un libro sobre corrientes estéticas en arquitectura. Aunque pocos manuales de sociología lo reconocen, la respuesta es simple: los sociólogos tienen también sus demonios personales, sobre 
los que les gusta curiosear. Investigar según la intuición y los demonios de cada cual es siempre arriesgado: uno puede terminar escribiendo una investigación de alcance limitado o, por el contrario, puede iniciar una nueva línea de investigación que puede llegar a tener impacto en una o otra literatura sociológica. En cualquier caso, y aun siendo arriesgado, el lector siempre preferirá leer el texto de un autor implicado hasta la médula en un trabajo novedoso que la enésima reflexión de un tema ya mil veces trillado por unos $u$ otros. Si el entusiasmo del autor es sincero, se contagia inmediatamente. Y si, además, arrastrado por la intuición, el autor consigue mostrar la utilidad de la sociología en ámbitos tradicionalmente alejados de su campo de investigación e incorporar nuevas ideas y retos para el científico social en una u otra literatura sociológica, mejor que mejor. Esto lo ha conseguido Mauro Guillén en el libro que aquí se comenta.

Este libro parte de un artículo previo publicado en la Administrative Science Quarterly, la revista más prestigiosa en sociología de las organizaciones, lo que ya da idea de la utilidad tanto de la pregunta como de los resultados de la investigación que ahora nos ocupa. En concreto, el libro trata de explicar los orígenes del movimiento modernista en arquitectura, y las razones por las que este nuevo estilo cobró más fuerza en unos países que en otros. Puesta en estos términos, la pregunta de investigación exige un marco de investigación histórico y comparado. El Reino Unido, Alemania, Francia, Italia, Rusia, España, México, Brasil y Argentina son los nueve casos que desgrana Guillén para encontrar respuesta a aquella pregunta.
Una primera dificultad, resuelta en el primer capítulo, es la definición del modernismo en arquitectura. Si bien el modernismo presenta distintas variaciones en distintos países, Guillén lo define según sus rasgos mínimos y en contraste con otros estilos contemporáneos. Un edificio modernista, ya sea una fábrica, un hospital, una gasolinera o un edificio de viviendas, está hecho para usar, no para admirar. Busca sobre todo la sobriedad y la simplicidad, la regularidad, funcionalidad y eficiencia antes que el ornamentalismo, la simetría o la imitación de la naturaleza propios de estilos clásicos. Los elementos básicos del modernismo son el acero, el cemento armado y el vidrio. Más importante, una construcción modernista es puramente racional, y aspira a reproducir y a ser contemplada como un artefacto mecánico, producto de la ciencia y racionalidad económica. Antes que a embellecer las ciudades con edificios sólidos, recargados o impresionantes en su monumentalidad, los modernistas preferían construcciones ligeras, simples, útiles, eficientes, modulares y, sobre todo, funcionales. Este funcionalismo y racionalismo de los arquitectos modernistas incluía un nuevo modelo estético, en donde la belleza de un edificio dependía de su semejanza con lo artificial y lo mecánico. Un edificio modernista debía ser una metáfora de la racionalidad humana, representada en su forma más sutil en el mundo de lo artificial y las máquinas. Esta ruptura con los moldes estéticos clásicos necesita encontrar una justificación, o, como decimos los sociólogos, necesitaba ser construida socialmente. Para ello, los modernistas entendían su trabajo no tanto como el de un artista en sentido estricto, sino como el de un reformador social. La arquitectura modernista, su funcionalidad y racionalidad, la economía de sus materiales y simplicidad deberían 
servir para elevar el nivel de vida de la población, reducir así los conflictos sociales y, al tiempo, lidiar con el problema del crecimiento de las ciudades. Antes que como un artista, el arquitecto modernista se presentaba como un reformador al servicio de la sociedad, un árbitro que utiliza la ciencia y el método, la planificación sistemática y la colaboración de otros científicos para progreso de la vida social.

Dadas estas características, no es de extrañar que el modernismo pudiera echar raíces en su etapa inicial en aquellos países que atravesaban periodos revolucionarios o trastornos sociales y políticos importantes, como la Rusia inmediatamente posterior a 1917, el México posrevolucionario de la segunda década del siglo xx, la España de la Segunda República, el Brasil del Estado novo, la Italia fascista o la Alemania de Weimar. En aquellos años tumultuosos, los modernistas tuvieron mejores oportunidades para neutralizar la resistencia de los arquitectos clásicos y encontrar los recursos necesarios por parte de Estados y empresarios orientados también a la búsqueda de la eficiencia, la industrialización, la racionalidad y la mejora de los niveles de vida mediante la producción y el progreso económico. De la misma manera, el modernismo no pudo cuajar en su primera fase en aquellos países relativamente libres de graves conflictos sociales como EE.UU., Francia o Gran Bretaña. En estos países el modernismo tuvo que esperar a que los arquitectos exiliados de Rusia, España, Italia y Alemania, una vez que consolidaron sus regímenes autoritarios o totalitarios, lo abandonaran en favor de clasicistas, monumentalistas, eclécticos o autóctonos, más útiles a la propaganda política.
El núcleo del argumento de Guillén, y que hace tan atractivo este trabajo, es el de los vínculos entre taylorismo y modernismo. Le Corbusier, para algunos el padre del modernismo, era un entusiasta de las teorías de Taylor. Lenin, una vez en el poder, también favoreció la introducción del taylorismo en las nuevas fábricas soviéticas, e impulsó la creación de una escuela técnica de arquitectura similar a la Bauhaus alemana. Por su parte, los arquitectos de la Bauhaus, de la misma forma que los pioneros italianos, consiguieron contratos con las empresas que más energías invirtieron en introducir el taylorismo, como fue el caso de la AEG, la Siemens, la Olivetti o la FIAT. De forma similar, uno de los máximos exponentes del modernismo español, Sert, discípulo de Le Corbusier, sólo pudo desarrollar su estilo propiamente modernista por oposición a Gaudí, un antitaylorista de estilo conservador, nostálgico y monumentalista, muy alejado del modernismo europeo. Fue allí, en fin, donde los modernistas cultivaron sus contactos y obtuvieron apoyo de Estados o empresarios más afines al modelo de la organización científica del trabajo taylorista, donde el modernismo cuajó con más fuerza en su fase inicial. Si bien en un principio puede sorprender esta vinculación entre taylorismo y modernismo, esto es, entre una teoría de organización del trabajo y una corriente estética, no debería extrañar, dado que ambos comparten los mismos motivos y tópicos, como la funcionalidad, la racionalidad, la simplicidad, la eficiencia, la utilidad, estandarización y mecanicismo. De hecho, los aportes del taylorismo a la arquitectura modernista fueron más allá de una mera inspiración estética, puesto que también implicó la aplicación de métodos tayloristas (como el empleo de ingenieros de métodos y tiempos, pro- 
cesos estandarizados, etc.) en la misma construcción de edificios modernistas.

La relación tan estrecha entre taylorismo y modernismo, ausente en las explicaciones clásicas de esta corriente artística, es un descubrimiento de primer orden en la investigación de Guillén. Pero el autor no se limita a describir esta relación, sino a explicarla. Más en concreto, el autor demuestra que la alianza entre arquitectos e ingenieros, materializada en las nuevas escuelas técnicas de arquitectura en oposición a las viejas Facultades de Artes y Oficios que todavía entendían la arquitectura como un arte, al modo de la pintura o la escultura, la explican las diferencias nacionales en las primeras manifestaciones del modernismo. Esta explicación, que Guillén defiende por medio de uso exhaustivo de datos comparativos que reconstruyen las redes sociales entre arquitectos, ingenieros, empresarios y elites políticas, encaja perfectamente, como señala Guillén, en las teorías neoinstitucionales de sociología de las organizaciones: el modernismo triunfó, en fin, allí donde sus promotores consiguieron definir la nueva profesión del arquitecto como un especialista más cercano al ingeniero que al artista, crear sus nuevas escuelas técnicas con el concurso de los ingenieros, y obtener los recursos económicos y la legitimidad de aquellos que más convencidos estaban de la utilidad, bondad y racionalidad de los métodos de organización científica del trabajo.
Al margen de sus resultados, esta investigación muestra, desde mi punto de vista, dos lecciones muy importantes: la de la utilidad de la investigación comparativa, y la valentía a la hora de embarcarse en un tema de investigación que «no está de moda». Aunque no se explicita en su libro, el trabajo de Guillén es en gran parte una reivindicación de los clásicos de la sociología. Frente a ciertas tendencias en la sociología contemporánea reacias a la investigación comparada, Mauro Guillén, al igual que los clásicos, insiste en la utilidad del método comparado. Más en concreto, este libro ha servido para descartar otras macroteorías sobre los orígenes del modernismo y defender, en su lugar y rigurosamente, una teoría alternativa de alcance medio que muestra mucho mayor poder explicativo; un resultado al que sólo se puede llegar comparando minuciosamente unos casos con otros. Comparar es la mejor forma de entender. $Y$ para entender es a veces muy útil hurgar o curiosear algo que aparentemente poco tiene que ver con, o está muy lejos de, lo que otros hurgan, curiosean o está de moda. Merton siempre nos recomendó seguir a nuestros demonios, allí donde la intuición, bien entrenada, nos llevara ([1961] 1973: 59-62)*. Esto es lo que ha hecho Mauro Guillén con éxito notable.

Roberto GARVÍA

\footnotetext{
* Robert K. Merton ([1961] 1973): «Social Conflict Over Styles of Sociological Work», en The Sociology of Science, Chicago, III.: University of Chicago Press, pp. 47-69.
} 